\title{
Poemas con título o sin él. Acerca de algunas opciones estéticas de Juan Ramón Jiménez
}

\author{
Georges GÜNTERT \\ Universidad de Zúrich
}

\begin{abstract}
El análisis de las opciones a favor o contra el título nos permite enfocar la trayectoria poética de JRJ desde otra perspectiva. Se observan, en efecto, cambios de actitud sorprendentes. Si la renuncia al título individual es constante en la fase melancólico-musical, que va desde Arias tristes hasta Pastorales, ocurre lo contrario en algunas obras de madurez y, sobre todo, en Diario de un poeta recién casado, donde el poema aspira a ser pensamiento-palabra capaz de conferir eternidad al instante.
\end{abstract}

Keywords: modernismo, técnicas impresionistas, simbolismo, poética de la madurez, titulogía

Creo que en la escritura poética, como en la pintura y en la música, el asunto es la retórica, «lo que queda», la poesía.

Juan Ramón Jiménez

Hay poetas que, a la hora de componer un poema, siguen el dictado de su pensamiento, que obsesivamente gira en torno a un mismo núcleo temático, hasta conseguir un texto orgánico, con una reflexión coherente y un asunto claramente identificable. Otros, más genuinamente líricos, se dejan fascinar por alguna imagen o cadencia rítmica que desata su imaginación y los induce a explorar la potencialidad expresiva del lenguaje, razón por la cual tienden siempre a dar prioridad a los valores sugestivos y musicales del discurso. Como figura representativa de la primera actitud se me ocurre pensar en ese gran «modernista ideológico» que fue Unamuno, y concretamente en su libro Poesías, de 1907, donde desde su «Credo poético» afirma que «el lenguaje es ante todo pensamiento» y que «algo que no es música es la poesía, / la pensada sólo queda» (Unamuno I969: I69)ㄷ․․ Decía Juan Ramón que Unamuno «no tenía percepción sensorial» y que desconfiaba de los estetas por su mayor afinidad con los pensadores; pero le admiraba como «poeta total» que se movía a gusto en las más diversas literaturas, clásicas y modernas (Jiménez I962: 98 y I76)². En el lado opuesto respecto a la poesía explí-

I «Credo poético» es el segundo poema del libro Poesías, editado en 1907.

2 Las denominaciones «modernista ideológico» e «ideólogo modernista», aplicadas a Unamuno, se encuentran en el curso sobre El modernismo del poeta de Moguer; cfr. Jiménez 1962: 
citamente reflexiva se sitúan, a mi modo de ver, el intimismo de Bécquer y el simbolismo de Verlaine, tan influyentes ambos en la poesía española de comienzos del siglo xx.

Ahora bien, el poeta atento a los asuntos que desea comunicar difícilmente evita titular sus composiciones, porque el epígrafe anuncia la idea dominante («Para después de mi muerte» o «En la muerte de un hijo», por citar ejemplos de Unamuno), resume el tema («Castilla», «Sísifo») o deja entrever una parte significativa del contenido («Denso, denso», que ha de entenderse como exigencia estilística en relación con el pensamiento poético). A los genios propiamente líricos, en cambio, nada les cuesta desatender la norma de rotular los versos: se contentan, en este caso, con poner un título de sección, como ocurre en los Romances sans paroles de Verlaine y en las «Rimas I a LXXVI» de Bécquer³. Opta por esta segunda solución el propio Unamuno, pero solo en circunstancias particulares y después de los años veinte. Es entonces cuando su gusto por la paradoja le induce a concebir poemarios atribuidos a personajes ficticios, como las rimas «de un poeta desconocido presentadas y presentado por M. de Unamuno», que por su común temática erótica no requieren títulos individuales. Las noventa y ocho rimas de su libro más becqueriano, Teresa, adoptan la estructura del cancionero, basada tradicionalmente en el orden numérico (Unamuno I969: 570-57I) ${ }^{4}$.

\section{Los comienzos de Juan Ramón: la herencia simbolista y el incipiente modernismo}

En cuanto a la preferencia por titular o no los poemas, Juan Ramón es de los casos más interesantes, puesto que practica alternativamente ambas técnicas. El problema está en comprender los criterios que le inducen a decantarse por una u otra solución. En sus libros juveniles, Ninfeas y Almas de violeta, más tarde rechazados, se atiene todavía al uso tradicional del título obligatorio, lo que condice con su actitud de considerar sus ideas y sus emociones como lo esencial del mensaje ${ }^{5}$. Sus cantos, según confiesa en «Oferto-

230. Pero en el texto nos referimos a sus observaciones críticas acerca de la limitada sensibilidad estética del bilbaíno. Sobre las relaciones de Juan Ramón con Unamuno véase también lo que escribe Gullón (2008: 56-59).

3 La editio princeps (Madrid I87I) es póstuma. Fue editada por los amigos del poeta, quienes, en cuanto al título de sección «Rimas», respetaron la voluntad del autor.

4 No hay que olvidar, al respecto, la última colección de rimas de Unamuno, reunidas en su obra Cancionero, Diario poético 1928-1936. También en ella son mayoría los poemas sin título (Unamuno 1969: 929-I424).

5 Hay muchos testimonios sobre el enérgico rechazo de su obra de juventud: $c f r$. sus conversaciones con Ricardo Gullón (2008: 64) o una entrevista de Juan Guerrero (2013: 67). En otro lugar aún puntualiza: «Con Rimas empezó mi reacción contra el modernismo agudo de Ninfeas, que me hizo caer del lado opuesto», cit. por Ángel González en su «Prólogo»a Jiménez 
rio», quieren ser «pedazos humeantes de [su] alma soñadora, / de [su] alma, peregrina de los nobles reinos de Oro, / de los reinos encantados donde viven las Quimeras» (Jiménez 1967: 1465). Es cierto que se descubren también temáticas subyacentes, más auténticamente líricas, como la obsesiva referencia al recuerdo de la muerte o la tensión entre la carne y el alma, que conocerá un significativo desarrollo en su obra de madurez. Pero la mayoría de los poemas de Ninfeas guarda un carácter programático, con títulos elocuentes como «Mis demonios» (que son el «ensueño», el «delirio» y el «sarcástico desencanto»), «Quimérica» o «Titánica». Es verdad que en Almas de violeta se percibe una diferencia tonal debida al predominio de la introspección y el recuerdo, pero la costumbre de anunciar las emociones ya desde el título (por ejemplo en «Tristeza primaveral», «Elegíaca» y «El Cementerio de los Niños») se mantiene. Aunque la imaginería y los juegos cromáticos procedan del simbolismo europeo (el «lago de sangre» en que flotan las «encantadas ninfeas»; o la «pálida niña» que «a la sombra del rosal de sangre» llora su perdida inocencia en un poema dedicado a Valle-Inclán), los modelos, a juzgar por las dedicatorias, son por ahora exclusivamente nacionales. Lo más modernista que los dos libros juveniles tienen son los colores de la tinta de su impresión, verde y violeta, y las referencias a personajes ilustres de la vida literaria del momento: Rubén Darío, Ramón del Valle-Inclán, Jacinto Benavente, Salvador Rueda, Manuel Reina, Manuel Machado y Francisco Villaespesa ${ }^{6}$. Lo demás es expresión de un genio «medio bohemio y medio anarquista» ${ }^{7}$, más próximo al romanticismo tardío que al esteticismo modernista, por más que Villaespesa, en el «atrio» o prólogo de Almas de violeta, le presente como representante del «Arte nuevo» y como defensor del «Arte por el Arte» (Jiménez 1967: 1517).

\section{Hacia un modernismo más auténtico: técnicas impresionistas en Arias tristes (1903)}

Con el libro Rimas (1902), escrito en su mayor parte en un sanatorio francés, inicia una búsqueda propiamente lírica, que supone nuevas lecturas y conduce a un cambio de orientación estética. «En la época de Burdeos quienes más me interesaron fueron Laforgue, Verlaine y Francis Jammes, la atracción de Baudelaire no la [sentí] hasta los veintitrés años», así recuerda Juan Ramón su propia formación de poeta (Gullón 2008: 8I). Nace, ahora, una poesía menos vinculada a las ideas y más intrínsecamente musical, se-

(2006: II).

6 Javier Blasco, en su «Introducción» a Antología poética, habla de «excentricidades tipográficas» y también de la «ausencia de [una] voz auténtica y crítica» (I987: 23).

7 Véase a este propósito el capítulo que un estudio recién aparecido dedica a Juan Ramón, considerándolo un «bohemio de guante blanco» (Del Olmo Iturriarte 2009: I5-30). 
gún sugiere el título becqueriano. Es indicativo de esta tendencia al lirismo el hecho de que solo la mitad de los setenta y tres poemas del libro continúen llevando título, mientras que la otra mitad está formada de rimas exentas de epígrafe ${ }^{8}$. Pero la novedad del tono se advierte incluso en los poemas titulados. En «Paisaje», por ejemplo, escrito cerca de Burdeos, la descripción del atardecer sobre un fondo de emociones subjetivas -concebida como un desleimiento «de formas y matices», mientras «una ascensión de bruma ahúma el vidrio del cielo»-, hace presentir un nuevo modo de 'pintar', en que los estados anímicos se compenetran con los colores del mundo observado (Jiménez 2006: 137-I38).

\section{PAISAJE}

Hacia oriente, las gasas del moribundo día funden jardín y cielo con dulce armonía de sus vagos matices: sobre un cielo violeta destiñe sus verdores el jardín. En la quieta placidez del conjunto no hay golpe vigoroso ni alegre que distraiga; es este un religioso desleimiento de tonos delicados; las lilas que están en flor, aúnan sus dulzuras tranquilas con la lejana fronda. Nada turba la calma de calor $[\ldots]$

Va la luz extinguiéndose lenta, suave y lenta; una lluvia de lágrimas parece que satura el espacio, cuando la noche crece cargada de misterios [...].

(Jiménez 2006: I37)

A pesar del carácter novedoso de algunos pasajes de Rimas, la primera poética auténtica de Juan Ramón no se define hasta Arias tristes (I903), cuyos melancólicos versos acabarán por darle la fama del «triste-andaluz» ${ }^{9}$. Arias tristes es un libro unitario, compuesto de setenta y seis poemas de estrofas romanceadas, enteramente sin títulos. La obra, tripartita ("Arias otoñales», «Nocturnos»y «Recuerdos sentimentales»), se concibe como un álbum de composiciones musicales («arias»), en el que cada sección se abre con la re-

8 En su Tercera antolojía poética (I898-I953), Juan Ramón vuelve a editar -con variantes y ahora con títulos- algunos textos de Rimas, como el núm. XVIII «Me he asomado por la verja» (Parque viejo) y el núm. XL «En el balcón, un momento» (Adolescencia). De esto se infiere que la opción a favor o contra el título está condicionada hasta cierto punto por el lugar (libro, antología, revista) en el que el texto se reproduce.

9 Aurora Luque, en su «Prólogo», recuerda a este propósito la reseña que Rubén Darío redactó para La Nación de Buenos Aires, gracias a la cual se divulgaría en el mundo hispano la imagen de «Juan Ramón triste-andaluz» (Luque 2010: Io). 
producción de una partitura de Schubert: Lob der Tränen, Serenade, Du bist die Ruh. En esta nueva fase creativa, el poeta se dedica a evocar atmósferas de una «monotonía encantadora», momentos de ensueño, Stimmungen, cuya melancolía se corresponde de algún modo con sus estados de ánimo, a la vez que lo representado va cobrando cierta autonomía. Y es que la concepción del poema ha cambiado. En Arias otoñales cada texto semeja un cuadro, un paisaje, con sus componentes imprescindibles: la niebla, el humo, la lluvia, las fragancias, los sonidos y la luz; estos elementos, sin ser un mero reflejo de la esfera sentimental del poeta, suscitan impresiones «indefinidas y vagas» que forman como un nimbo protector entre el yo y su angustia existencial. El yo se contenta con adoptar un papel de observador, mirando hacia aquellos escenarios «desde su balcón», a través de «los cristales» o de la «ventana entreabierta», y de esta manera consigue una representación algo distanciada de su propia «tristeza». Ocurre que el yo, no pudiendo «besar a su amada», acaba dando sus «besos al paisaje / que sabe por qué me muero...»; y el texto sigue así: «paisaje, guarda mi ensueño...» (Jiménez 20I0: 50$)^{\text {Io }}$. Cabe destacar la singularidad de estos paisajes dotados de memoria e iluminados por la luz reflejada de la luna. Mientras que el «dulce sol de octubre» dora el paisaje, derramando sobre los árboles sus últimos rayos otoñales (por lo que forma parte de una estética del tiempo que pasa y de la melancolía), la luna representa la luz inmanente: la conciencia intrínseca del texto. ¿Será por eso que aparece casi siempre en los últimos versos del poema? «Sobre la plácida / tristeza de la campiña / sube la luna dorada» (final del poema III); «Sobre los álamos blancos / de la dormida ribera, / una luna rosa y triste / va subiendo entre la niebla» (final de IV); «Y allá en la niebla de Oriente / que ha velado las montañas, / va subiendo sobre el campo / una luna anaranjada» (final de XII); «Flota el humo blanco; el valle / se ha quedado triste y solo; / las esquilas van llorando / bajo la luna de oro» (final de XVIII). Arias otoñales ofrece, por tanto, cuadros atmosféricos auto-conscientes, aptos para convertirse en metáforas del espacio poético:

¿Por qué el alma llora tanto,
muerta para sus amores,
si sabe que hay otro llanto
temblando sobre las flores?
La tarde sueña, dormida
en la niebla flotadora:
Daré niebla a mi alma herida
para ver si así no llora.

(Jiménez 20I0: 49, la cursiva es mía)

Io En esta y en las citas siguientes es nuestra la cursiva. 
El paisaje atmosférico-musical surge en sustitución de la realidad insatisfactoria a la que se ve condenado el yo, y consigue velar, gracias a su consistencia nebulosa, la crisis ontológica del poeta: «El vaho de la arboleda / vela la fronda lejana, / alejando dulcemente / la ribera abandonada» (Jiménez 20I0: 39). Es evidente que Juan Ramón desea ocultar el fondo tenebroso de su ser detrás de esa melancólica bruma, pues tiene a bien declarar: «La bruma es dulce en la tierra, / lo aleja todo, es soñado / bajo su velo el jardín... / ¿No es bruma lo que lloramos? / Cuando no hay bruma en la tierra / buena es la bruma del llanto; / si no se alejan las cosas / nosotros las alejamos.» (Jiménez 20I0: 57, la cursiva es mía). Estos escenarios hacen pensar, más que en paisajes andaluces o castellanos, en cierta pintura impresionista, sobre todo en la de Claude Monet ${ }^{\mathrm{II}}$, pero, más allá de estas sugerencias pictóricas, hay que tener en cuenta el impacto de las lecturas francesas: "La lune est rouge au brumeux horizon; / dans un brouillard qui danse, la prairie / s'endort fumeuse et la grenouille crie / par les joncs verts où circule un frisson», escribe Verlaine en «L'heure du berger», un soneto de la sección «Paysages tristes», que figura en su bien conocido Choix de poésies, la antología manejada por Juan Ramón y los hermanos Machado (Verlaine I896: 29; Gullón 2008: 8I).

En la segunda sección, Nocturnos, que se abre con un verso de Verlaine, la luna se convierte en interlocutora principal del yo ${ }^{\mathrm{I2}}$. Con su «lumbre de azucena» transforma la oscuridad de la noche en idilio, ofreciendo calma y consuelo, sobre todo cuando su aparición viene acompañada de sensaciones complejas, como el frescor de una «brisa perfumada de jazmines» (XXXVIII) o la audición nocturna de una sonata de Schubert (XXXIX):

\begin{abstract}
XXXI
Para dar un alivio a estas penas que me parten la frente y el alma, me he quedado mirando a la luna a través de las finas acacias.
\end{abstract}

\footnotetext{
II Conviene no olvidar un importante dato biográfico: Juan Ramón, antes que poeta, fue pintor; su vocación se mantuvo hasta los dieciséis años. Sobre la estrecha relación entre su poesía y la pintura, consúltese Crespo (1974: 9-26).

I2 La cita es esta: «Au calme clair de lune triste et beau, / qui fait rêver les oiseaux dans les arbres» (Fêtes galantes). Pero ya en Helios, núm. 7, octubre de 1903, pp. 30I-304, Jiménez había publicado la nota «Pablo Verlaine y su novia la luna», que menciona en su carta a Enrique Díez-Cañedo de agosto de I9Io; cfr. Alegre Heitzmann (2006: 235). Y en otra carta de enero de 1905 al filólogo Viriato Díaz-Pérez confiesa: «Le diré honradamente, puesto que va a tratar de esas influencias literarias, que en Verlaine encontrará mucho aroma del de mis libros [...]. Para mí, el mejor poeta sería el que encontrara en un corazón como el de Heine una música como la de Verlaine» (Alegre Heitzmann 2006: 146).
} 


\begin{abstract}
En la luna hay un algo que sufre entre un nimbo divino de plata, hay un algo que besa los ojos y que seca llorando las lágrimas.

Yo no sé lo que tiene la luna que acaricia, que duerme y que calma y que mira en silencio a los tristes con inmensas piedades de santa.

Y esta noche que sufro y que pienso libertar de esta carne a mi alma, me he quedado mirando a la luna a través de las finas acacias.
\end{abstract}

(Jiménez 2010: 103)

En la tercera sección, Recuerdos sentimentales, predomina el erotismo galante. Los cuadros que se interponen entre el poeta y sus obsesiones se pueblan ahora de seres humanos: pastores con sus rebaños, niñas en compañía de sus abuelas que evocan los cuentos de la infancia, y, sobre todo, esas misteriosas jóvenes vestidas de blanco, que representan la vida de los afectos, a la que el poeta da muestras de preferir sus lecturas (L, LVIII, LXIV). ¿Son novias repudiadas o difuntas? Solo en el ensueño logra el yo besar a sus amadas (LXII), que sin embargo no consiguen poner fin a su soledad.

El poeta diserta en varias ocasiones sobre el cambio que Arias tristes supuso en su carrera. Así, en una carta del mes de julio de 1943 a Luis Cernuda, indica como elemento característico de su evolución la menor importancia que fue otorgando, a partir de aquel libro, a lo temático: «Mi proceso se ve bien en mi obra publicada. En mis primeros libros, Almas de violetas, Ninfeas, Rimas, los poemas tienen asunto y son muy largos; luego, en Arias tristes, Jardines y Pastorales, el asunto va desapareciendo, y el romance, que es entonces la forma preferida [...], se abrevia» (Jiménez 1977: 59). Esto no implica que esas composiciones carezcan de contenido; se entrelazan entre sí, de hecho, por medio de símbolos afines -huertos, riberas, brumas, campiñas-, pero el asunto, ahora, es más difícil de definir. Ante estas monótonas descripciones el lector tiene la sensación de mirar siempre el mismo paisaje: varían las figuras, pero permanecen idénticas las relaciones entre el yo y sus ensueños, que, por tener la fuerza de alejar las obsesiones, desempeñan una función indubitablemente terapéutica.

En la misma línea de Arias tristes se mueve el libro Jardines lejanos (1904), que se distingue a su vez por su unidad tonal y sus composiciones exentas de título. El símbolo principal es ahora el jardín, metáfora evidente del espacio poético. Gracias a la perfección formal de estos versos, Juan Ramón adquiere la fama de príncipe de los modernistas: ha asimilado las leccio- 
nes de Heine, Espronceda, Bécquer, Rosalía de Castro, Verdaguer, Poe, de Musset, Verlaine, Laforgue, Rodenbach, Samain y Jammes, a la vez que continúa inspirándose en la tradición áurea de la literatura hispana. Con cinco amigos ha fundado, en 1903, la revista Helios, en cuyos catorce números se publicarán textos originales de Rubén Darío, los hermanos Machado, Unamuno, Benavente y Azorín, por no hablar de las traducciones de poetas como Verlaine. Ha conocido, o va a conocer pronto, a las personalidades más relevantes de la vida intelectual del país, entre ellas, Ortega y Gasset y Francisco Giner de los Ríos, cuyas obras enriquecerán su pensamiento de poeta. Jardines lejanos representa, en efecto, una cumbre de su lírica juvenil. En sus tres secciones, «galantes», «místicas» y «dolientes» (esta última dedicada a Antonio Machado), el poeta permanece fiel a la técnica de las "variaciones sobre un tema», ostentando un «melancólico virtuosismo», que es, a los ojos de Luis Antonio de Villena, su rasgo distintivo:

El libro es largo y desde hoy [...] podríamos decir que algo monótono, en el opresivo tema del jardín triste, de las novias o amadas enfermas, lánguidas o imposibles, en medio de la bruma, el decaimiento, la nostalgia, el otoño, la suave desesperación de un alma que busca y que sólo halla languidez, angustia, vacío, ansias de renovación, en una palabra, el retrato de un espíritu decadente (Villena 2007: I0).

A lo cual el poeta, siempre muy consciente de su «monotonía», respondería:

¿Repetición de las mismas cosas? Sí. Una obsesión de felicidad. También el amor repite los besos hasta lo indecible, y cada uno tiene un encanto nuevo (Jiménez I967: II5I).

\section{El retiro del poeta a Moguer (I906-I9I2) y las últimas «obras de juventud»}

Algunas rimas de Pastorales pertenecen a lo primero que el poeta compuso durante su estancia en el pueblo natal. Esta vuelta a la naturaleza, con un Lied de Schumann o un motivo de la Sinfonía pastoral al oído, es también un regreso a la poesía del campo, por parte de un caminante que se deleita en «encontrar rimas entre la hierba» (Jiménez 1967: 53I). La valoración estética de lo popular, tan importante para los poetas influidos por el krausismo, comienza a manifestarse en sus recursos al folklore, desde las canciones de cuna hasta los villancicos, y esta atención a la tradición lírica del pueblo le ayuda a objetivar sus propios estados de ánimo (Del Olmo Iturriarte 2009: 48). Digamos que su tristeza de poeta, omnipresente aún en la 
primera sección, se va atemperando ante la vitalidad de la gente de pueblo. Algunos poemas se atribuyen a la voz del «pastor Galán», quien expresa sus emociones en el lenguaje de la aldea. Pero los más se mantienen fieles a ese clima de melancólica soledad y son tan semejantes entre sí que no necesitan distinguirse con títulos individuales. Cuando el poeta finalmente consiga publicar este libro, no antes de I9II, pedirá a su amigo Gregorio Martínez Sierra, responsable de la edición, una disposición de los poemas análoga a la de Arias tristes: «Las composiciones irán sin ningún título: numeradas con números romanos - de I a IX- y en el orden que guardan en Teatro de ensueño [...], como las demás partes de Pastorales; la distribución y el ajuste también iguales» (Alegre Heitzmann 2006: 264) (13. $^{13}$

Con Baladas de primavera (1907) se llega al cambio, que implica, desde el punto de vista temático, la renuncia al intimismo. El poeta canta ahora las alegres estaciones de la primavera con «nostalgia de salud», con esperanza de curarse, a sabiendas de que va a componer «baladas un poco exteriores», con una música humana «menos íntima que la de las cosas» (Jiménez I967: 737). Sus baladas, comparables a un ramo de flores, se diferencian en cuanto a la ocasión, tema y tono: contrastan los colores («Balada de la amapola», «Balada de la soledad verde y de oro») y discrepan los asuntos («Balada del mar lejano», «[...] del avión», «[...] del almoraduj»). Frente a esta llamativa diversidad, no extraña que Juan Ramón vuelva a titular los poemas para conferir la necesaria originalidad a cada composición. Lo cierto es que, de ahora en adelante, va a practicar de nuevo ambas soluciones. En Elegías, La soledad sonora y Melancolía (I9I2) predomina aún el ordenamiento de las composiciones numeradas, mientras que Poemas mágicos y dolientes y Laberinto (I9I3) se nos presentan como libros mixtos, con algunas secciones tituladas y otras, no. Para determinar las razones de cada opción, sería necesario un análisis detallado de la poética inherente a cada una de estas obras. Pero el espacio limitado de este estudio me obliga a pasar por alto estas consideraciones y a centrarme en la obra de la madurez.

\section{La preferencia por el poema titulado en algunas obras de madurez (I913-I926)}

De vuelta a Madrid, donde vive en la Residencia de Estudiantes, Juan Ramón comienza la etapa tal vez decisiva en su evolución. No solo porque conoce a su futura esposa, Zenobia Camprubí, que va a cambiar su destino de hombre y de poeta, sino también porque publica una serie de libros de

I3 «Carta a Gregorio Martínez Sierra», mayo de I9II. Teatro de ensueño es una obra de G. Martínez Sierra, en la que Juan Ramón había incluido ocho poemas suyos, que quiso publicar nuevamente en su libro Pastorales. 
gran intensidad que señalan un giro radical en su concepción del arte: tras Estío, que no aparecerá hasta I9I6, escribe, con ocasión del viaje a Nueva York en compañía de su futura esposa, una de sus obras maestras, Diario de un poeta recién casado (I9I7), que contiene al mismo tiempo el relato de la génesis de una nueva poética. Se trata de un libro excepcional, caracterizado por la alternancia de poemas en prosa y poemas en verso, y cuyas anotaciones van, dado el género de diario poético, casi siempre fechadas. A esta cumbre artística le seguirán otras obras de alta calidad autorreflexiva, como Eternidades (I9I8), Piedra y cielo (I919) y Belleza (I923). Pues bien, en cuatro de los cinco libros que hemos mencionado, predomina la opción a favor del título, que puede considerarse, en cierta medida, una tendencia característica de su estilo de madurez. La excepción es Eternidades, compuesto de numerosos fragmentos de intensa reflexión metapoética, que, por obedecer todos al mote "Amor y poesía, cada día», no necesitan anuncio o etiqueta individual (Jiménez 2007: 39).

Empecemos con uno de los poemas más comentados del Diario, el número XLIII, «Cielo», uno de los textos que mejor ejemplifican la nueva poética de Juan Ramón ${ }^{14}$. Su poética de madurez se basa en el arte de mirar el mundo «con ojos recién estrenados», «libre de la visión convencional» (Blasco I987: 59). Consiste, asimismo, en la captación del instante a través de la palabra, es más: en un acto de aprehensión del mundo por parte del espíritu, o «del alma» según prefiere decir el poeta, cuyo pensamiento se nos manifiesta en la expresión poética, que confiere a ese instante un valor universal. El poema mismo, en cuanto resultado de una triple actualización (del mundo, del yo y de la palabra), alcanza el valor de sujeto, y, como tal, bien merece que su singularidad se destaque con un título. Hay mucha sabiduría oriental en el pensamiento poético de este Juan Ramón, y lo confirma el prefacio «Saludo del alba», traducido del sánscrito, que invita a vivir intensamente el «momento presente» en cuanto capaz de contener en sí «la esencia misma de la vida» (Jiménez 20II: 43). Esa misma apertura hacia un presente siempre renovable se encuentra en algunos poemas de Eternidades, como, por ejemplo, en el segundo, que reza: «Plenitud de hoy es / ramita en flor de mañana. / Mi alma ha de volver a hacer / el mundo como mi alma» (Jiménez 2007: 42); o bien, en un fragmento del célebre número III: «jIntelijencia, dame / el nombre exacto de las cosas! / ...Que mi palabra sea / la cosa misma, / creada por mi alma nuevamente [...] (Jiménez 2007: 43, la cursiva es mía). Pero detengámonos ahora en el poema «Cielo»:

I4 Tengo presentes, sobre todo, las dos interpretaciones de Gustav Siebenmann (I973: 219220) y de Jacques Geninasca (200I: 9I-98). 


\section{CIELO}

Te tenía olvidado,

cielo, y no eras

más que un vago existir de luz, visto - sin nombre-

por mis cansados ojos indolentes.

Y aparecías, entre las palabras

perezosas y desesperanzadas del viajero,

como en breves lagunas repetidas

de un paisaje de agua visto en sueños...

Hoy te he mirado lentamente,

y te has ido elevando hasta tu nombre.

(Jiménez 20II: 87)

Escrito en versos libres (pero con endecasílabos y alejandrinos en los puntos estratégicos del discurso), el poema "Cielo» se divide en dos secuencias principales A y B, en las cuales se contraponen un modo de «ver» y un modo de hablar distraídos (vv. I-9) a la «mirada» consciente, capaz de devolver «el nombre» a las cosas y, con ello, su ser-para-el-sujeto (vv. IO-II). En la primera secuencia, dividida a su vez en dos segmentos (aI, vv. I-5 vs. a2, vv. 6-9), el cielo es una presencia poco advertida por el viajero, como algo que está allí sin afectarle de modo particular y que se le aparece apenas como «un vago existir de luz». Es percibido, además, solo fragmentariamente, «en breves lagunas repetidas» y entre «las palabras perezosas y desesperanzadas del viajero», quien, en sus conversaciones, no sale de su estado de apatía. Pero la mirada consciente, en B, consigue una actualización de la realidad, y todo cambia en estos últimos versos. Es curioso que el término «nombre» aparezca aquí en lugar de "cumbre», que uno se esperaría encontrar al final («te has ido elevando hasta tu...»), pero esta sustitución obliga a tener en cuenta la doble dimensión, espacial y verbal, del discurso. El acto de aprehensión de la bóveda celeste, esto es, del espacio contemplado, se realiza como acto de lenguaje que genera el espacio del poema, y el título, situado en el cenit de este, al explicitar el significado de ese «nombre» en «Cielo», viene a desempeñar la función denominadora central. Dicho de otro modo, la última palabra del texto, «nombre», es al espacio contemplado lo que la palabra del título, «Cielo», es al espacio verbal.

Frente a la unicidad que acabo de atribuir a este título, se me podría objetar que en el Diario, y precisamente en la segunda sección de la travesía y antes de la composición que nos ocupa, aparecen otros dos textos denominados "Cielo», a saber, los números XXVIII y XXXIV, y además uno llamado «Cielos» (XXXVI), que propone el mismo título, pero en plural. Después del poema XLIII, en cambio, ya no se encuentra nada análogo, a no ser, en la 
sección americana, el poema «Sky», que dice así: «Como tu nombre es otro, / cielo, y su sentimiento / no es mío aún, aún no eres cielo» (Jiménez 20II: IO8). La falta de identificación del poeta con la lengua extranjera impide por ahora que la nueva realidad americana se transforme en algo suyo.

En cuanto a los dos poemas precedentes, deben verse como aproximaciones al poema revelador (XLIII), aun cuando cada uno de ellos tenga su propio significado e interés. En el número XXVIII, el poeta intenta asemejar el cielo al mar (del cual dice, en otro lugar, que se mueve incesantemente «sin encontrarse a sí mismo»), sin advertir aún la dimensión vertical del espacio celeste. Lo único que intuye es la enorme extensión física de ambas realidades y la tendencia del viajero a desatenderla: «Cielo, palabra / del tamaño del mar / que vamos olvidando tras nosotros» (Jiménez 20II: 7I). De la otredad del «cielo» respecto al «mar» se da cuenta, sin embargo, en el poema XXXIV, donde asocia su acceso a una dimensión más amplia al proceso de crecimiento experimentado por él en su juventud. Acostumbrado a jugar en su cuarto, situado cerca del jardín, a nivel del suelo, el niño, un día, se hizo adolescente y como tal se atrevió a explorar también las demás estancias de la casa: «Igual que, cuando / adolescente, entré una tarde / a otras estancias de la casa mía / -tan mía como el mundo-, / y dejé, allá junto al jardín azul y blanco, / mi cuarto de juguetes, solo / como yo, y triste...» (Jiménez 20II: 78). Aunque el poeta comprenda aquí la necesidad de una expansión hacia lo alto, su reflexión sobre lo que experimentó en el umbral de la adolescencia se tiñe de nostalgia, lo que le impide captar lo específico del espacio celeste. Finalmente el poema «Cielos», en plural, tiene que ver con el sucederse de los días y las noches, que el muchacho atravesaba leve «como una mariposa»: se trata de otro recuerdo de la infancia, que poco contribuye al descubrimiento de la nueva poética (Jiménez 20II: 80).

Los textos que vienen a continuación del XLIII y que comparten con él ese mismo grado de perfección, son poemas de amor para Zenobia (como «Silencio», «Idilio» o «Serenata espiritual», en la sección «América del Este»), o bien diálogos del viajero con el mar, el cual, en la travesía de retorno, se convierte en el objeto principal de sus meditaciones ${ }^{15}$. De los cuarenta y un poemas de la sección «Mar de retorno», doce contienen la palabra «mar» en el título o en el primer verso, y en otra docena los diversos aspectos del océano -sus colores, su extensión e incesante movimiento-constituyen el tema principal del discurso. A diferencia del espacio celeste que, una vez actualizado, incluye también al espíritu creador, el mar se le aparece como una fuerza física antagonista, «salvaje», «borracha», «loca», y por eso mismo

I5 A la cuestión de por qué cambió el título del Diario de un poeta recién casado, Juan Ramón contesta: «Cambié el título porque quería destacar la importancia que en su gestación tuvo la presencia del mar, el contacto con el mar. El libro está suscitado por el mar y nació con el movimiento del barco que me traía a América» (Gullón 2008: 67). 
reacia a las definiciones: asume las características de una realidad imprevisible e indomable, hasta parecerse «a un cielo rebelde, caído de los cielos» (Jiménez 20II: 22I). Las definiciones, que se suceden con una rapidez desconcertante, son, de hecho, contradictorias: el mar ya se asemeja a una fuerza destructora (y, en el mejor de los casos, a un gigante bueno como «San Cristóbal», que levanta los «navíos al cielo»), ya a un «criadero sin fin de corazones», esto es, a un magma creador; es «contemplador eterno del sol y las estrellas», y por tanto ojo del universo, o bien, ¡qué horrible visión!, "plenitud de oscuridades», abismo sin fondo. Una de las formulaciones más reveladoras se halla, a mi modo de ver, en el poema CLXXXV, cuyo primer verso dice: «Tu nombre, hoy, mar, es vida», por lo que el título de esta composición no puede ser sino «Vida». El mar como vida contradictoria que en algún momento responde «al latido del corazón» y que, las más veces, nos desconoce.

\section{Bibliografia}

Alegre Heitzmann, Alfonso (2006), Juan Ramón Jiménez. Epistolario I, I898I9I6, Madrid, Publicaciones de la Residencia de Estudiantes.

-. (20I2), Juan Ramón Jiménez. Epistolario II (I9I6-I936), Madrid, Publicaciones de la Residencia de Estudiantes.

Bécquer, Gustavo Adolfo (I87I), Obras, Madrid, Fontanet.

-. (I976), Rimas, ed. de José Carlos de Torres, Madrid, Castalia.

Blasco, Javier (20I0), «Introducción», en Juan Ramón Jiménez, Antología poética, Madrid, Cátedra, pp. I3-IO2.

Crespo, Ángel (1974), Juan Ramón Jiménez y la pintura, San Juan de Puerto Rico, Editorial Universitaria, Universidad de Puerto Rico.

Del Olmo Iturriarte, Almudena (2009), Las poéticas sucesivas de Juan Ramón Jiménez, Sevilla, Editorial Renacimiento.

Geninasca, Jacques (200I), «Juan Ramón Jiménez: Cielo», en Fröhlicher, Peter et al. (eds.), Cien años de poesía. 72 poemas españoles del siglo XX: estructuras poéticas y pautas críticas, Berna, Peter Lang, pp. 9I-98.

Guerrero Ruiz, Juan (2013), «Impresiones (1913)», reeditado en Soledad González Ródenas (ed.), Juan Ramón Jiménez. Por obra de instante: entrevistas, Sevilla, Fundación José Manuel Lara, pp. 66-70.

Gullón, Ricardo (2008), Conversaciones con Juan Ramón Jiménez, prefacio de Pedro Lastra, Sevilla, Sibila-Fundación BBVA, 2008.

Jiménez, Juan Ramón (I957), Tercera antolojía poética (I898-I953), Madrid, Biblioteca Nueva.

-. (1962), El modernismo. Notas de un curso (1953), Madrid-México-Buenos Aires, Aguilar. 
- (1967), Primeros Libros de Poesía, recopilación y prólogo de Francisco Garfias, Madrid, Aguilar.

-. (1969), Primeros Libros de Prosa: I, ordenación y prólogo de Francisco Garfias, Madrid, Aguilar.

-. (I977), Cartas literarias, edición e introducción de Francisco Garfias, Barcelona, Bruguera.

-. (2006), Rimas (I900-I902), Obras de Juan Ramón Jiménez, vol. I, prólogo de Ángel González, texto preparado por Javier Blasco, Madrid, Visor.

-. (2007), Eternidades, Obras de Juan Ramón Jiménez, vol. I7, texto preparado por Almudena del Olmo Iturriarte y Francisco J. Díaz de Castro, prólogo de Luis García Montero, Madrid, Visor.

-. (2007), Jardines Lejanos (I904), Obras de Juan Ramón Jiménez, vol. 3, prólogo de Luis Antonio de Villena, texto preparado por Javier Blasco, Madrid, Visor.

-. (2010), Arias tristes (1903), Obras de Juan Ramón Jiménez, vol. 2, prólogo de Aurora Luque, texto preparado por Carmen Morán Rodríguez, Madrid, Visor.

-. (20II), Diario de un poeta recién casado, Obras de Juan Ramón Jiménez, vol. I6, texto preparado por Javier Blasco, prólogo de Luis Muñoz, Madrid, Visor.

Siebenmann, Gustav (I973), Los estilos poéticos en España desde I9oo, versión española de Ángel San Miguel, Madrid, Gredos.

Unamuno, Miguel de (1969), Poesía, en Obras completas, vol. VI, Madrid, Escelicer.

Verlaine, Paul (I896), Choix de poésies, avec un portrait de l'auteur, París, Bibliothèque Charpentier. 